\title{
Linguistic Landscapes in Multilingual Nepal: Urban Context
}

Basanta Kandel

\begin{abstract}
Diversity in the linguistic landscape is a common phenomenon in multilingual country Nepal. We observe varied textual forms of language and signs in public spaces and spheres that surround us. Therefore, this study concerns to analyze the signs in linguistic landscapes in multilingual urban settings in Nepal. It reveals the status of different languages, deals with issues related to multilingualism, language policy, linguistic diversity, minority languages, hierarchies, and users. Besides, it observes intricacies of language contact and choice, power and status of language groups, and sociolinguistic situation. For this, observation and interpretative method of qualitative research were employed, 150 photographs were purposively snapped from five urban spaces in two month time. The signs were analyzed, compared and contrasted using a thematic approach with relevant theoretical backup. The finding revealed that the choice of language on signs bases on sign writer's skill, presumed reader and symbolic value (Spolsky \& Cooper, 1991). The study explored that the majority of urban linguistic landscapes are occupied by English signs, and English imperialism is a greater challenge for Nepali and vernacular languages. It is inferred that diversity in linguistic landscapes is the concrete manifestation of multilingual society where languages battle for their existence; therefore, the multilingual policy is the stipulation of the day.
\end{abstract}

Keywords: language battle, linguistic landscapes, presumed reader, sign writer, symbolic value

\section{Introduction}

Nepal identifies as a wonderful juncture and one of the gorgeous countries in the world in terms of its linguistic and ethnic diversity. Nepal is bestowed with a gift of tongues (CBS, 2002) and varied languages have made significant contributions to its diversity. The Constitution of Nepal (2015) in its preamble states that Nepal is a multi-ethnic, multi-lingual, multi-religious, multi-cultural country having diverse regional characteristics. The society has a complete mixture of people from diverse backgrounds; socio-economical, political, religious, linguistic, cultural, ethnic which shapes the landscapes of the territory. Among different landscapes in the society, a linguistic landscape reflects the clear portrait of a certain region. When people move, the surrounding languages of a particular region or landscape attract their attention which makes them think about language variety, style, structure, tone, manner, and purpose. Most of the people have no attention to the linguistic landscape which surrounds them; however, the closer observation and study of language texts expressed in public space are increasing unfailingly (Gorter, 2006).

Linguistic Landscape (LL) is an emerging and dynamic field of research in applied and sociolinguistics which attempts to understand the motives, uses, ideologies, varieties and contestations of multiple forms of languages as they are displayed in public spaces (Chanda, Hossain \& Rahman, 2018). It refers to any display of visible written language in public places. It is 'the language of public road signs, advertising billboards, street names, place names, commercial shop signs, and public signs on government 
buildings a given territory, region, or urban agglomeration' (Landry \& Bourhis, 1997). Further, it includes many new types of signs: electronic flat-panel displays, LED neon lights, foam boards, electronic message centers, interactive touch screens, inflatable signage, and scrolling banners (Gorter, 2013). The linguistic landscape is a multifaceted phenomenon that relates to a multitude of perspectives and disciplines like advertising, education, economics, history, media, semiotics, sociology, and urban geography and so forth. The use of language in its written form in public space is the main focus of linguistic landscape studies and research in multilingual Nepal.

Nepal is a multilingual, multicultural and multiracial country since time immemorial, and the National Census (2011) records 123 languages among them Nepali, Maithili, Bhojpuri, Tharu, Tamang, Newari, Bajjika, Magar, Doteli, and Urdu are on top ten lists. Moreover, the Language Commission Nepal (LCN, 2017) informs 10 language scripts exists in the country: Devnagari for Nepali, Maithili, Bhojpuri, Ranjana for Newari, Sambota for Tibetan and Sherpa, Sirijunga for Limbu, Rong for Lepcha, Bangla for Bangali, Tamu for Gurung, Arabi for Urdu, Roman for English, Akkha for Magar. Correspondingly, the LCN announces that among 123 languages, only 19 languages are in a safe zone which has over one lakh speakers, and more than 37 languages are in endangered condition. Besides, Ethnologue (2019) informs that of 122 living languages in Nepal, 109 are indigenous, and 13 are non-indigenous, among them, 8 are institutional, 18 are developing, 28 are vigorous, 58 are in trouble, and 10 are dying.

In these linguistic circumstances, the country has entered the Federal system after the proliferation of the new Constitution in 2015 abolishing the hereditary monarchical regimes and centralized ruling system. The federal, provincial and local government as an autonomous body can formulate state policies and laws, preserve language, script, art, culture, and other heritage (The Constitution of Nepal, 2015). This transformation of the political regime has opened up new insights, yet contested, discourses concerning language policy and planning. Therefore, the future of Nepal's language policy depends largely on how federal, provincial and local governments manage the linguistic diversity and landscapes of the country and have its language policy, planning and practices.

Therefore, I attempted to explore how the languages in Nepalese urban areas exist and establish domination in public spaces through this study. Further, the study informs about sign writer's skills, presumed reader and symbolic value attached to the signs, power, and status of languages, and sociolinguistic situation of the country. Considering all these scenarios and facts, I explored and analyzed the languages displayed on signs in public space and which reveals the status of different languages in linguistic landscapes in multilingual Nepal. This study will be relevant for the concerned stakeholders like the language policymakers and arbiters, researchers, government and bureaucrats, and politicians to make the policy and address the issue of linguistic diversity and linguistic landscapes of urban territories, especially in Nepal. I found no study has been carried out in this particular issue in linguistically diverse areas: Kathmandu, Kirtipur, Lumbini, Damauli and Kalaiya city which remains a gap plus uncovered. The findings contribute to reducing the gap in knowledge by providing the information on linguistic landscapes and Nepalese urban and sociolinguistic context which can assist the government authorities, language 
policy makers and arbiters in Nepal to formulate the language policy and planning. Therefore, I would like to explore, add and share the Nepalese urban context experiences to the body of knowledge.

\section{Review of Literature}

To strengthen the knowledge of linguistic landscapes, theories and principles, and the existing literature, experts and researches in the field, I have reviewed various newspapers, books, articles, journals, theses, dissertations, policies, websites, online from home and abroad, and put forward here. Based on the literature review, I have stated my understanding related to linguistic landscapes and its phenomenon in the following subsections.

\section{Linguistic Landscape}

Linguistic landscape refers to the visibility and prominence of languages on public and industrial signs in a given territory or region (Landry \& Bourhis, 1997). The first study in the field of the linguistic landscape as 'Rosetta Stone' which was an ancient stone with writing in three different languages, found near Rosetta in Egypt in 1799, now kept in British Museum in London. It embodies many of the intricacies of language contact, language choice, and linguistic hierarchy that form the substance of linguistic landscape research (Coulmas, 2009). The study is the analysis and interpretation of the relationships between languages and spaces, which is a blooming field in current sociolinguistics. Gorter (2006) defines the linguistic landscape as 'the social context in which more than one language is present' forming multilingualism. In a narrower sense, the word linguistic landscape is synonymous with the concept such as diversity of languages, linguistic situation, general language situation or sociolinguistic context but in broader sense, it is the linguistic mirror of the dynamics of our globalised society. The use of language in its written form in public space is the main focus of linguistic landscape studies (Gorter, 2006). Linguistic landscape has been defined variously by various experts in the field as 'the linguistic items found in the public space' (Shohamy, 2006, p. 110), 'environmental print' (Huebner, 2006, p. 31), 'the words on the walls' (Calvet, 1990), 'the word on the street' (Foust \& Fuggle, 2011 as cited in Gorter, 2013), 'multilingual cityscape' (Gorter, 2013), 'general language situation or linguistic diversity' (Gorter, 2006), 'the decorum of the public life' (Shohamy, 2006, p. 10). Many linguistic landscape studies are confined to one specific geographic area, which often is a city, but could also be a street, a neighborhood, or even a whole country, or it could be a comparison between more than one of these levels of analysis (Gorter, 2013). The linguistic landscape of a territory can serve two basic functions: informational function and symbolic function.

Informational function. Linguistic landscape serves as a distinctive marker of the geographical territory inhabited by a given language community (Bourhis, 1992). It serves to inform in-group and outgroup members of the linguistic characteristics, territorial limits, and language boundaries of the region they have entered (Landry \& Bourhis, 1997). The diversity of language present in the linguistic landscape can be seen as a concrete manifestation of the linguistic and cultural diversity of ethnolinguistic groups inhabiting a particular territory or region.

Symbolic function. The inclusion or exclusion of the in-group and out-group language on public signs can serve a symbolic function which has an effect on its member within a bilingual and multilingual 
setting. The presence and absence of rival languages in specific domains of the linguistic landscape can come to symbolize the strength or weakness of competing ethnolinguistic groups in the intergroup setting (Landry \& Bourhis, 1997). It is also important to note that whatever language is most dominant in the linguistic landscape automatically conveys a message that language has strength, power, status, significance, and vitality in the area. In contrast, languages that have little or no presence in an area are devalued and are seen as having little use in public affairs (Landry \& Bourhis, 1997). Factors relating to symbolic functions include meanings interpreted concerning cultural affiliation, identity, power relations, and language status (Dagenais, et al., 2009).

Linguistic landscaping has become a popular means to inform and relate to sociology, education, ecology, literacy, linguistic anthropology, psycholinguistics, and socio-cultural studies (Shohamy \& Waksman, 2009). Studying the linguistic landscape of an area can determine a great deal about the people that live in that area, what language ideologies are at play, which languages have power and prestige, and which are marginalized (Dixson, 2015). The creation of the linguistic landscape involves many actors creating signs, commissioning signs, installing signs and most importantly people who read, notice and interpret the signs. The linguistic landscape of an area reveals about the people who live there, the languages spoken, what languages are valued, and what official or de facto language policies are in place in the neighborhood, city or even country.

More holistic factors are now being taken into account when studying the linguistic landscape; these include the context surrounding a sign, people who interact with the sign, genre, function, and purpose (Huebner, 2009). Signs need to be viewed more holistically since the reader of the sign does not simply interact with the linguistic text found on the sign. Shohamy and Gorter (2009) also seek to broaden the scope of linguistic landscaping beyond simply signs, suggesting sounds, images, and graffiti are also important to the linguistic landscape. Spolsky (2009) notes that these different types of signs have informational and symbolic meanings and how the symbolic meanings are interpreted depend on the type of sign, discusses authorship in signs as being local or global. Cenoz and Gorter (2009) state that 'the use of different languages in the sign...reflects the power, status and economic importance of the different languages' (p. 57). Ben-Rafael (2009) points out how power-relations and collective-identity are often at play in the linguistic landscape. Language is seen as a marker of identity and using a language in a public sphere asserts that the language group is present. It is also a symbolic marker of what language speakers may or may not do business in a commercial area.

Linguistic landscapes often reflect language policy in an area. Very few territories in the world have an official policy regarding the language of signs in the public space; however, language policy can take other forms (Cenoz \& Gortor, 2009; Hult, 2014). Official languages of an area or a racial or ethnic group in power can be dominant in a linguistic landscape. When a language is regulated in schools or government proceedings in a particular territory it can also become dominant in the linguistic landscape. Any time a government on any level (national, state, municipal) regulates language in any way, it is likely to be reflected in the overall linguistic landscape of the territory, regardless of whether the policy addresses language on public signs or not. 
In Malaysia, signs that display 'Manglish', a mixture of Malaysian and English, can incur hefty fines (Spolsky, 2009). In Bangkok, signs that contain no Thai are taxed more heavily than signs that contain Thai (Huebner, 2009). Educational language policies and policies regulating language in the media and economics are often reflected in the linguistic landscape (Cenoz \& Gorter, 2009). For example, in San Antonio, Texas there is a large, growing population of Spanish-speakers as well as a transient population of Mexicans who cross the international border from Mexico often. Despite a significant number of Spanish speakers, the linguistic landscape is predominantly English. This could be in part due to local educational language policy focusing on English-only education, as well as strong activism favoring English-only in the community, government, and education (Hult, 2014). Even where no official language policy is present, the political ideologies of an area make themselves known within the linguistic landscape.

Huebner (2006) examined the linguistic landscapes of 15 Bangkok neighborhoods to explore questions of language contact, language mixing, and language dominance. It provided a linguistic framework for the analysis of codemixing types, further highlighted the importance and influence of English as a global language. It examined the signs from government sources versus those from the private sector. It also revealed the extent of linguistic diversity in a large metropolitan area like Bangkok by a comparison of various neighborhoods. For the study purpose, the team had photographed the main city centers and analyzed 613 signs of different categories. Moreover, the study offered evidence of a shift from Chinese to English as the major language of wider communication in the city. From a linguistic perspective, the study showed the influence of English on the development of Thai, not just in the form of lexical borrowing, but also in the areas of orthography, pronunciation, and syntax. At the same time, the study provided evidence of a nascent Thai variety of English. This study assisted me to understand the basic concept of the linguistic landscape and the research techniques in the area.

Backhaus (2006) studied about multilingual signs in Tokyo which was based on empirical research conducted in 2003. Special attention was given to the distinction between official and nonofficial multilingual signs. Within the 28 survey areas, a total of 11,834 signs were counted, of which 2321 were classified as multilingual. It was demonstrated that the two types of signs exhibit some essentially different characteristics about the languages contained and their arrangement on a sign which were interpreted using the notions of power and solidarity. While official signs were designed mainly to express and reinforce existing power relations, nonofficial signs make use of foreign languages to communicate solidarity with things non-Japanese. The study revealed that around $80 \%$ of the signs in the center of Tokyo were monolingual Japanese sign. Both types of signs have their share in changing and challenging Tokyo's linguistic landscape. The study discussed well official and nonofficial multilingual signs used in Tokyo, and the existing power relation between languages.

Malinowski (2009) points out "more often, the domain of human agency behind the linguistic landscape remains unnamed" (p. 108). He studied shop signs in Koreatown in Oakland, California. He recorded and categorized the signs, and interviewed shop owners about language and design choices, how the sign is intended to be perceived, and how the sign is perceived, to gain a more holistic view of the signs and their informative and symbolic meanings. In actuality, the linguistic landscape is incredibly 
complex, and theories and methodologies in studying it can be drawn from a variety of fields, including linguistics, sociology, politics, and cultural studies (Barni \& Bagna, 2009, as cited in Dixson, 2015). This study informed me about the research methodology and design in the field of linguistic landscape which I employed accordingly.

Dixson (2015) analyzed the multilingual linguistic landscape of Buffalo, New York which is the home to thousands of immigrants and refugees from across the globe having diverse cultures, desires for the futures, and their home languages. The study examines how these linguistic communities are represented in the linguistic landscape, and what deeper symbolic meanings signs in the linguistic landscape hold for them. All signs on six streets were photographed and categorized. Signs entirely or partially in non-English languages were plotted on an electronic map and examined for potential symbolic meanings. If reflected that the linguistic landscape of Buffalo was vastly English dominant, echo some of the diversity of the area. Since languages are tied to identity, relegating languages can promote ideologies against ethnic groups tied to those languages. Overall, the linguistic landscape reveals the need to learn English to function in American society, but inconsistencies are found throughout the city that reflects the presence of nonEnglish speakers in the area, and occasionally the promotion of their culture and language.

Wang (2015) examines multilingual university campus signs in Japan, a new attempt to expand the scope of linguistic landscape study. The case study on the languages used in signs on Ito campus presents the features of the construction of the campus linguistic landscape where bilingual JapaneseEnglish signs compose the majority of campus signs, with the Japanese language used as the dominant language. The results indicate that for their academic life, students value bilingual ability a lot; in their daily lives, students maintain multilingual contact to a certain degree. This study is a synchronic record of the construction of the campus linguistic landscape, thus it can be used as a basis for comparative and diachronic studies in the future.

Bastola (2017) critically analyzes the discourses used in the hoarding board/advertisement in the Nepalese socio-cultural context focusing on ideology and power. His qualitative research in the interpretative paradigm study reveals the fact that the use of language changes due to the influence of social and political ideology and power. His observation and analysis conclude that the language used in hoarding board advertisements have excessive use of English and Nepali language discourse which is caused due to the power, hegemony, and dominance of both languages in Nepalese context to attract the consumers to sell their products. Similarly, the study indicated that most of the hoarding board advertisements have used English terminologies in the form of Nepali orthography because of terminological and translation problems. The advertising is multilingual, multifaceted and multidimensional and does not need the equal length and specific language, but of writer's choice and preferences. His study was limited to only 50 hoarding boards placed in different parts of Kathmandu valley. The study motivates me to study on the field in Nepalese multilingual urban contexts with some theoretical knowledge and ideas.

Chanda, Hossain and Rahman (2018) conducted a comprehensive study with the linguistic landscaping of the Pabna context in Bangladesh where very few respondents of different professions were bilinguals (Bangla and English) and rest were monolinguals (Bangla)). The study revealed that the influence 
of colonial language in Pabna area reflected through the signboards and other signs. The signboards of public spaces are mostly bilingual with English and the native language of Bangladesh but the signboards of government offices are mostly written in Bangla. The study revealed that Bangla is the official and de facto national language as well as lingua franca, but English, having treated as EFL, is prevalent across government, law, business, media, and education, therefore, regarded as the de facto co-official language.

Shukla and Singh (2018) studied about Mumbai which attempted to investigate the multilingual environment of India. As quantitative research, around 400 pictures of language signs were taken from different locations within the south Mumbai. The study analyzed the multilingual signs found in Mumbai indicated how the multilingual linguistic landscape is constructed under the current language policy of India. The study also focused on trends of LL in public space which includes advertising, billboards, posters, official (top-down signs) and non-official (bottom-up signs) road signs, and so forth.

In nutshell, Shohamy and Gorter (2009) point out that people create the language of the public space, therefore, the landscape communicates messages conveyed by people, which often have a deeper meaning than what is seen on the surface. Spolsky (2009) highlights that several participants are involved in the process of making a sign, and suggest more research are done to incorporate these participants into research on public signs. Ben-Rafael (2009) notes that the linguistic landscape is a complex system in which many actors are involved in creating and interpreting messages and meanings. Cenoz and Gorter (2008) point out that the linguistic landscape has economic value as well.

The reviewed theoretical and empirical studies on linguistic landscape in different countries and urban contexts: Malaysia, Bangkok, Tokyo, New York, Japan, Kathmandu, Bangladesh, and Mumbai have greatly inspired and informed me theoretical and practical knowledge to my understanding of the area, and to accomplish the study in Nepalese urban context. Also, several books, articles, journals, dissertations, and websites have strengthened me to make the research more comprehensive and logical. Taking the fundamental knowledge and viewing earlier research studies, I made and outlined the theoretical and conceptual framework, prepared research design and methodology to accelerate this study. Though various studies have been taken in a foreign context, I apprehend the need for a similar kind of study in the Nepalese context which can conduit the existing gaps in knowledge and append a block in the research foundation in the area of linguistic landscape in the multilingual urban context in Nepal.

\section{Methodology}

This study employs observation and interpretative method of the qualitative research under 'interpretative paradigm' which suggests the reality is indirectly constructed based on individual interpretation and is subjective (Cohen, Manion \& Morrison, 2007). For the purpose, 150 photographs were collected purposively with a digital camera from five urban spaces: Kathmandu, Kirtipur, Damauli, Lumbini, and Kalaiya within two months period. The studies inform, the cities are linguistically diverse and have the existence of over 25 languages. Further, the signs and photographs were documented, categorized, observed, analyzed and interpreted, compared and contrasted using a thematic approach with relevant theoretical back up to find the intricacies of language contact, language choice and linguistic hierarchies in 
linguistic landscapes. The photographs were taken from the open streets, in front of the buildings, shops, hotels and restaurants, supermarkets, business complex, offices, institutions, and monuments. All signs and photographs were included to gain a holistic picture of the overall linguistic landscape of the city. I focused on how linguistic landscape as a public arena, languages battle for the existence and establish the domination of space; therefore I took the photographs of different signs of urban environments.

\section{Results and Discussion}

This section reviews, analyses, and interprets the phenomenon of linguistic landscape in the Nepalese context especially, five major cities that are discussed thematically as per the objectives require. The collected data are broadly interpreted and analyzed into three broad themes which underpin on the theory of Spolsky and Cooper (1991) who proposed three conditions for the choice of language on signs: sign writer's skill, presumed reader and symbolic value. These three conditions apply to all signs, but their significance in the preference of one language or another may vary from sign to sign (Gorter, 2013). Moreover, the other two themes have been created which are supported by theoretical foundations.

\section{Sign Writer's Skill}

Language on signs has a deeper, symbolic meaning than what the direct, informative message of the sign is (Landry \& Bourhis, 1997). The creation of the linguistic landscape involves many actors creating signs, commissioning signs, installing signs and most importantly people who read, notice and interpret the signs. Though signs usually have an informative function, one that directs gives information or implores the reader in some way, signs also have a symbolic function, one that speaks to an underlying ideology (Landry \& Bourhis, 1997).

Among the three proposed condition in their study of the languages of Jerusalem by Spolsky and Cooper (1991) the choice of language on signs depends on 'sign writer's skill' which means writing a sign in a language you know that is a necessary condition. The sign-writer can speak and write the language(s) on the sign to a certain degree of proficiency which is closely related to the skills of the sign writer. The following signs displayed in public space in Damauli and Kathmandu state the fact that as per the knowledge and skill of the writer the signboards of the shops and firms have been written where writers have used mostly English language terms: Trade, Center, Fresh, Juice, Dairy, Emporium, Medical, Help, You, Service, Center, Urgent, Photo, Binding, Lamination, Color print, Photocopy, Sticker Print, Bill Pad, Stationery, Gift Items in Nepali orthographic form. The signs indicate that the boards have been prepared as the knowledge and skill of the sign writer's which informs us that English language influences presents in both contexts. Further, the perception is, the sign writers are not confirmed to English language, words, punctuation, and spelling, but feel comfortable in Nepali forms in public space. The practice further supports the hegemony and power of influence of English which has an exclusive impact on Nepalese society, commerce, business, education, and tourism, and is preferred and expected in each arena of human life. 


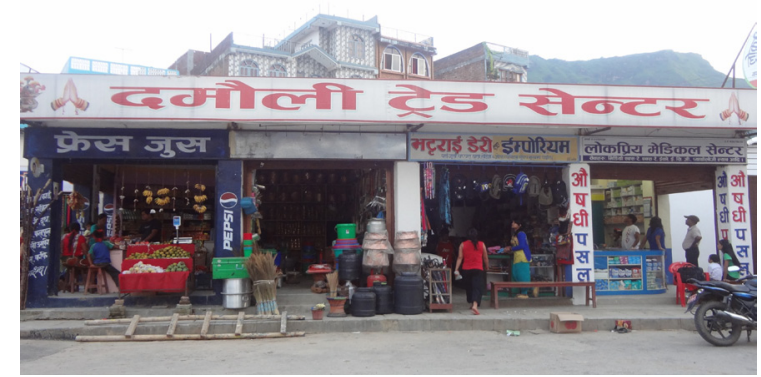

Figure 1

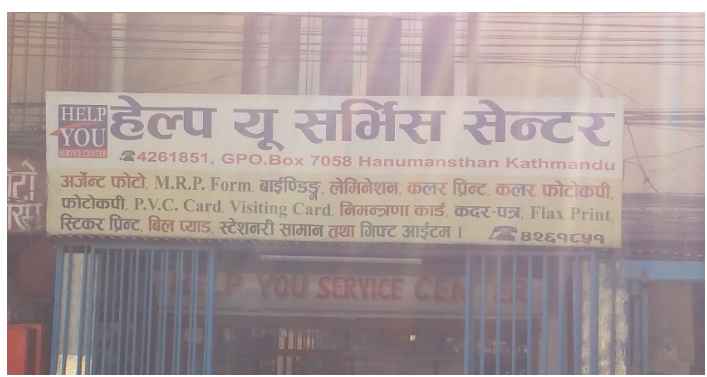

Figure 2

Figures $1 \& 2$. Reflect the glimpse of linguistic landscapes in Damauli and Kathmandu where the English terms are mostly used in Nepali orthographic forms as per the knowledge of the sign writer's skill.

\section{Presumed Reader}

Spolsky and Cooper (1991) further advocate that the choice of language on signs depends on 'Presumed reader' which refers to writing a sign in the language that can be read by the public you expect to read it. It prefers to write signs in the language or languages that intended readers are assumed to read and interpret. This condition has an economic motivation and informative function.

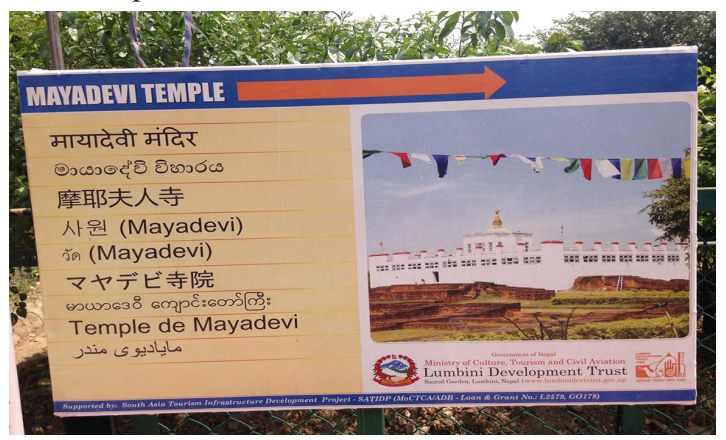

Figure 3

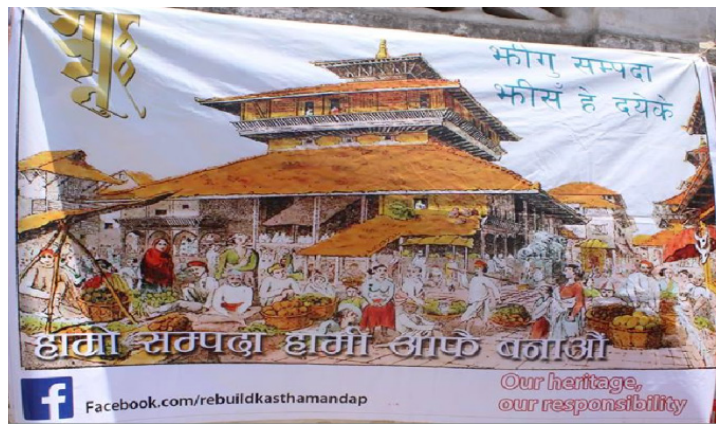

Figure 4

Figure 3. The importance of multilingualism for promoting cultural heritage in Lumbini near Mayadevi Temple which displays 10 different languages: English, Nepali, Chinese, Urdu, Japanese, Korean and others focused on presumed readers.

Figure 4. The poster in Hanumandhoka, Kathmandu reveals Newari, Nepali and English language which are given equal value in the heritage site considering the presumed visitors and readers.

\section{Symbolic Value}

Symbolic value condition prefers to write signs in your language or in a language with which you wish to be identified (Spolsky \& Cooper, 1991) and relates to more political, socio-cultural motivation and language loyalty. Throughout the world, the linguistic landscape reveals competing for language ideologies, struggles for power and prestige, language policy, and provides a map of linguistic territories (Cenoz \& Gorter, 2008). People create the language of the public space; therefore, the landscape communicates messages conveyed by people, which often have a deeper meaning than what is seen on the surface. 
Signs within the linguistic landscape serve both informational and symbolic functions which include both government and private signs (Landry \& Bourhis, 1997). The following signs snapped in Kathmandu and Kirtipur intense the symbolic value and sign writers' ideology where Chinese and Newari language are used as they desire to be identified with.

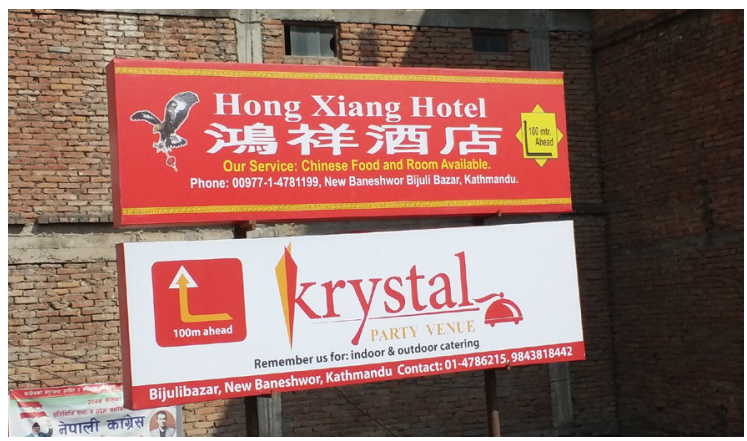

Figure 5

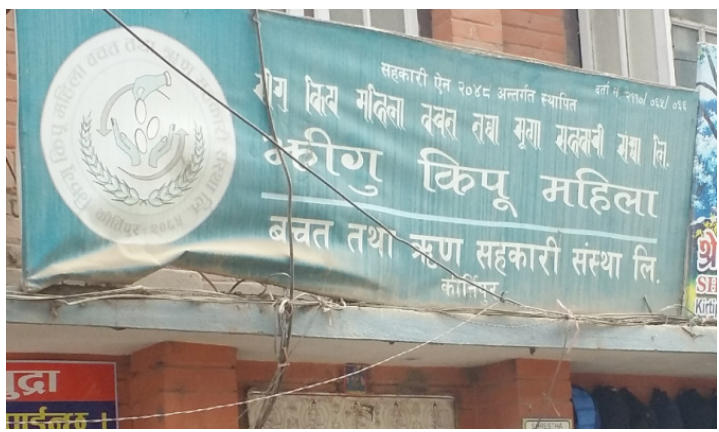

Figure 6

Figure 5. The sign in New Baneshwor, Kathmandu shows that Chinese and English languages are symbolically valued. It reflects the writer wants to be identified with the Chinese language rather than others.

Figure 6. A cooperative institution's signboard at Kirtipur focuses on Newari and Nepali language, but Newari is given the priority because of the Newari community and language dominance in the region.

\section{Language Battle in Public Space}

The linguistic landscape is a public arena where languages battle for existence and establish the domination of space (Shohamy, 2006). Linguistic landscapes as an ecological arena that goes beyond written texts of signs and includes oral language, images, objects, placement in time and space, and also people (Gorter, 2013). They posit fluid and fuzzy borders to include all possible texts that emerge in public space. Therefore, public space is not neutral, but a negotiated and contested arena which offers a challenge of further understanding the essence of language in public space (Shohamy \& Waksman, p. 329). Gorter (2013) states that linguistic landscapes items are mechanisms of language policy that can perpetuate ideologies and the status of language in public space (p. 197). The following pictures capture the scenario of language battle, multilingual creativity and linguistic fluidity in linguistic landscapes in Kathmandu, Kirtipur, and Kalaiya.

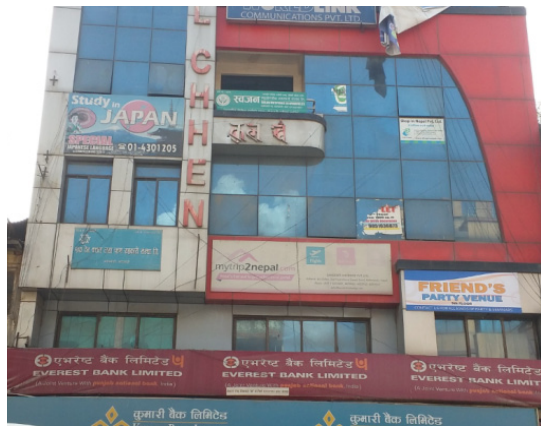

Figure: 7

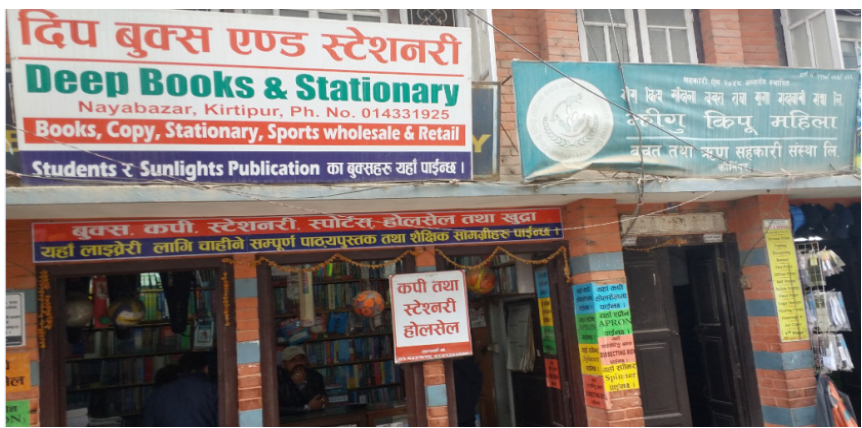

Figure: 8 


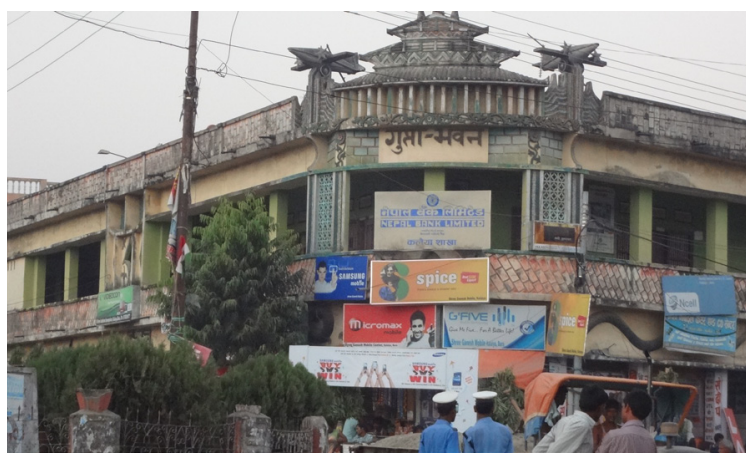

Figure: 9

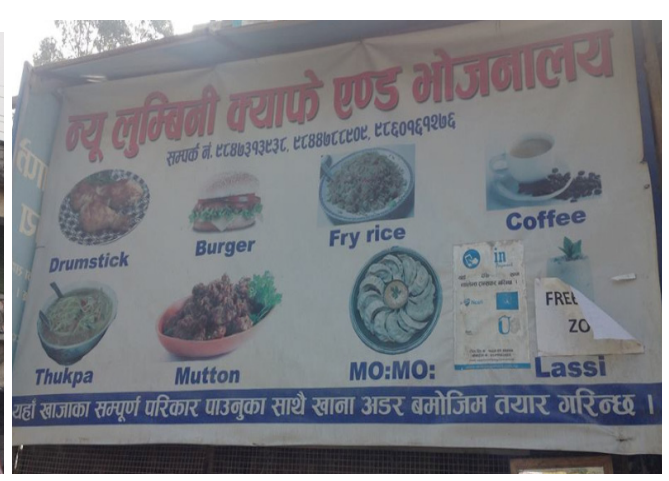

Figure: 10

The figures 7, 8, $9 \& 10$. Reflect the reality of language battle in linguistic landscapes in Kathmandu, Kirtipur and Kalaiya where different languages, signs and words from Nepali, English, Chinese, Newari, Hindi have been displayed with a special focus. The priority is given to like the interest of the sign writer, linguistic and ethnic dominance in the region.

Therefore, linguistic landscapes not only reflects the status of different languages in society but also acts as a force shaping how languages are being perceived, battling and used by the population.

\section{Linguistic Fluidity in Public Space}

Linguistic fluidity refers to the free flow of language crossing all the barriers. It is attached to the presentation and performance on language beyond the style and delivery, structure and tone, words and rhythm which makes the communication ease (Anonymous, n. d). It practices language flexibly in expression which develops new understanding and language practices beyond the academic standard practices. It is the combination of two or more languages that keeps the task moving forward that can be seen in urban landscapes, educational settings, and classrooms. Linguistic fluidity makes obvious that we cannot separate our languaging from how we perceive the world. Linguistic landscape can be a creative space where linguistic boundaries are challenged and new language practices are invented with fluid practices. Language policy embraces local diversity and redefines the use of language as a creative tool for public and fluid language use (Phyak, 2017). It provides as critical insights into examining how the dominant ideologies of language as a fixed entity do not embrace social reality in public spaces.

It concerns effective communication, function rather than form, cognitive activity, as well as language production. Linguistic fluidity includes code-switching, code-mixing, translanguaging which is an indeed a powerful mechanism to construct expression and understanding across language groups, a part of multilingual society. Moreover, linguistic fluidity is the flexibility of bilingual users to take control of their learning and expression depending on the context in which they are performing. The following signs (figure 11 and 12) taken in Kathmandu and Kirtipur, display the fluidity of languages in public space which is termed as 'linguistic fluidity'. 


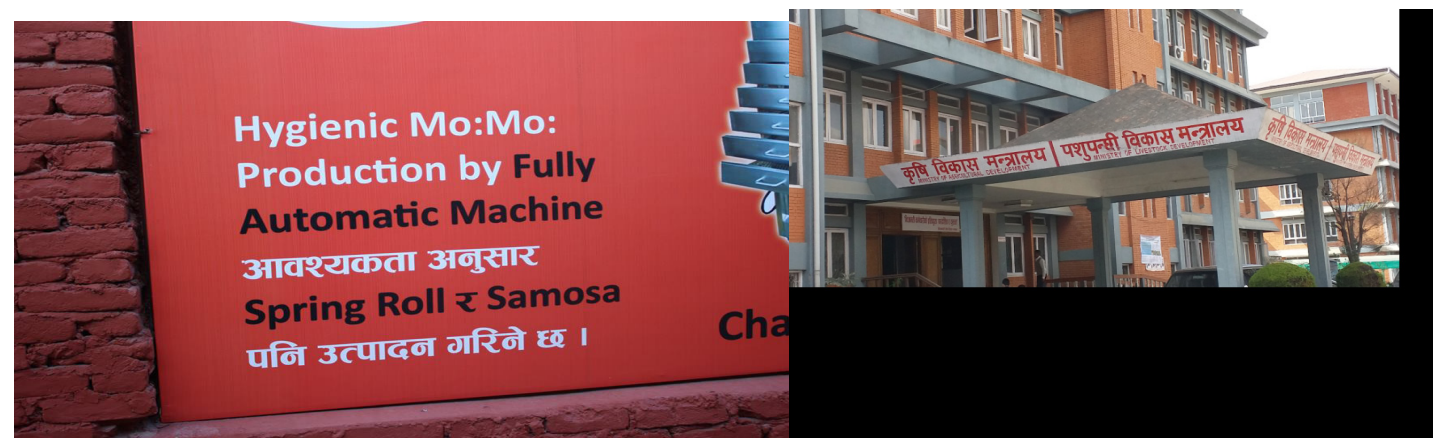

Figure: 11

Figure: 12

Figure $11 \& 12$. Reflect the linguistic fluidity in multilingual urban context in Kathmandu.

\section{Power and Use of English in Public Space}

The charm and glory, power and prestige, pride and identity of English have attracted entire citizens of the world, and Nepal is not an exception (Kandel, 2018). English serves as a link language to communicate with the speakers of different linguistic backgrounds, has become a basic need in these days. The use of English in Nepal seems as powerful as the government's act and policy. English in Nepal has captured all the sectors, and the people are being hypnotized and running after it. It has become able to change the ideologies, interests, and wills of the people about the world and its phenomena. Shrestha (2016) states:

Despite Nepal is a relatively small geographical area with a large number of languages, the international language English is considered the dominant language in this country due to its massive spread and use in media, education, diplomacy, business, and tourism. (p. 106)

English serves as the key external link in education, politics, commerce, science and technology, military alliances, entertainment, and tourism. People have a high craze on the English language knowingly or unknowingly in Nepal. English stands as the most prestigious language in Nepal due to its power and popularity. People take it as a matter of pride and prestige, therefore the gravity of the English language has been powerful. Giri (2015) mentions:

The status of English in Nepal has been changed in the last seven decades. Adopted first as a 'foreign' language, English, in recent years, has become an indispensable part of life for the Nepalese people. It is presently used as an additional language, second language and even primary language in many socio-economic and educational domains in Nepal. (p. 94)

Considering this fact, urban linguistic landscapes in Nepal are covered with English signs which have blurred the concept of the Nepali language as an official language. The swiftly growing presence of English in linguistic landscape, especially in cities has shadowed the existence of official language Nepali and other vernacular languages, and regarded as the de facto co-official language despite the fact that the New Constitution of Nepal, 2015 addresses in the article (6) and (7) about the languages of the nation and official language like this:

Article 6: All languages spoken as the mother tongues in Nepal are the languages of the nation. 
Article 7: (a) The Nepali language in the Devnagari script shall be the official language of Nepal.

With the spread of English as a global language, linguistic landscapes are becoming increasingly multilingual and even English dominant in government and non-government offices, schools and universities, business firms, commercial areas, shops and hotels (Dixon, 2015). American, British companies bring their products and services in the cities of Nepal with the English language which has extensively augmented the amount of English in the linguistic landscape. English is globally seen as the language of prestige, modernity, success, sophistication, and youth and is found most predominately in advertisements and commercial areas (Cenoz \& Gorter, 2009). They state that "the use of different languages in the sign... reflects the power, status and economic importance of the different languages" (p. 57). Ben-Rafael (2009) points out how power-relations and collective-identity are often at play in the linguistic landscape. In Nepal, the majority of signs in urban contain English form and used as prominent on main streets in commercial areas. The excessive presence of English in Nepal advocates a direct link between English and consumerism, fashion and modernity, urbanization and globalization which ultimately results in the vernacular languages in shadow. Following the multilingual reality of the country, Article 32, clause 1 and 3 of the Constitution of Nepal, 2015 has made the provision of the right to language and culture of the entire population.

(1) Every person and community shall have the right to use their languages.

(3) Every Nepalese community residing in Nepal shall have the right to preserve and

promote its language, script, culture, cultural civilization and heritage.

Furthermore, the constitution has furnished to establish Language Commission for the first time in the country's history which is stated in article 287 that is legally responsible to address language issues in Nepal like official language, protection, promotion and development of languages and mother tongues, and to study, research and monitor languages.

When we analyze the constitution, it has opened the use of mother tongue in local level and local offices; this can be an upward step of opening the constitutional door for the transformation of Nepal towards the multilingual nation. In federal Nepal, no doubt the country will transform into the multilingual nation system. The states can use the local languages in their administration and offices for governmental purposes. For the central government and in between central and state government and among different state government there will be a necessity of one or more link language(s).

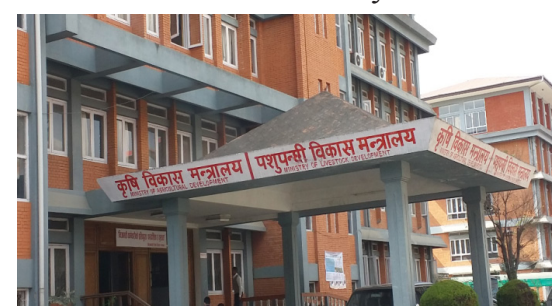

Figure: 13

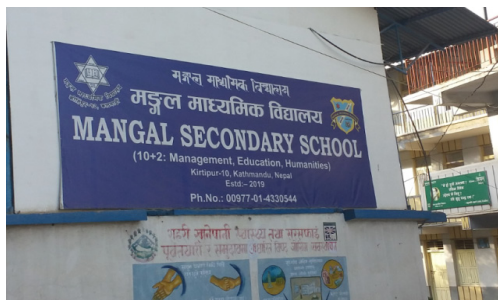

Figure: 14

Figures $13 \&$ 14. Taken in Singhdurbar Premise Kathmandu, (Ministry of Agricultural Development and Ministry of Livestock Development) and Kirtipur (a government school). 
Figure 13 and 14 reflect the reality of the power of English language in linguistic landscapes where English is used as the capacity of co-official language in the signboards. The first sign includes bilingual terms: Nepali and English while the second has given priority to multilingual: Newari, Nepali, and English. Though, both of the institutions are government owned, should prioritize the official language 'Nepali', but have focused Newari and English as co-official or de facto language.

The entire study represents a linguistic landscape scenario of the urban multilingual context of Nepal. Linguistic diversity, bilingualism, and multilingualism is a common phenomenon of Nepali urban where languages struggle, battle and dominate each other for their survival. Employing the observation and interpretative method of qualitative method, I snapped 150 signs, then observed, analyzed and interpreted, among them 90 contained English language and 50 contained Nepali and 10 signs were in other languages; Newari (in Kathmandu), Magar (in Damauli), Urdu, Bhojpuri and Hindi (in Kalaiya) and 10 different languages in the Lumbini Heritage Site. One sign contained Chinese characters, 7 signs were in Newari language (i.e. Nepal Bhasha) in Ranjana script, one sign was in Magar in Aakha script, two signs contained Urdu script, one was in Bhojpuri, one was partially Hindi and Nepali, and one contained Korean characters. During the study, it was found that the name of the government and private institutions were monolingual, multilingual and monolingual where majority (nearly 40\%) signboards were monolingual written (Nepali, English, Newari, Hindi and so on) half (i.e., 50\%) were bilingual written and the rest (nearly 10\%) were multilingual written. The choices of language on signs depend on sign writer's skill, presumed reader and symbolic value where language battle, linguistic fluidity, code-mixing, translanguaging and dominance of English were reflected on the signs. To summarize, the study meets the intense of objectives, and informs guides and shares genuine empirical and practical knowledge for the academia and further research in the respective field, especially in the Nepalese urban context.

\section{Conclusion and Implications}

This study was concerned to analyze the signs in linguistic landscapes in multilingual urban settings in Nepal which proposed to observe intricacies of language contact, language choice and linguistic hierarchies in linguistic landscapes, the power, and status of different language groups, and sociolinguistic situation of urban areas of the country. For the purpose, I employed observation and interpretative method of qualitative research, accordingly, 150 photographs were purposively collected from five different urban spaces. The photographs of different linguistic landscapes in the cities reveal the fact; linguistic landscapes have excessive bilingual and multilingual practices, code-switching, code-mixing, and translanguaging processes in the signs. The multilingual, multifaceted and multidimensional signs have greatly contributed to promote the services and businesses in the urban. Therefore, the people in the urban spaces have developed intercultural competence and multilingual awareness because of signs displayed in diverse languages with their cultural flavor. Most interestingly, I found that most signs have English terms in the Nepali orthographic form which strengthens the power, attraction, charm, and hegemony of English in public spaces. English signs were found drastically larger than the non-English signs which show and foremost that English is a dominant language and is necessary for survival. Though the government has 
not announced English as an official language, the data reveals that the English language is excessively used in signs as an official language and lingua-franca in the Nepalese urban context. The government and private offices and business firms' signs have bilingual displays (i.e., Nepali \& English). The urban areas linguistic landscapes are mostly (nearly 60\%) occupied with English language and the rest (nearly 40\%) in Nepali and other languages. In the urban areas, Nepali and English are commonly seen at different government offices, public places and on public commercial signs. Even the signs of the government and not-government offices are bilingual and even multilingual. The majority of signs are inscribed bilingually using both Nepali and English while some are monolingual written either in Nepali, Newari or English. The extreme use of English and Nepali, the vernacular languages and indigenous languages are battling for the existence in the urban linguistic landscapes, which might further create unpleasant situations for their survival. In reality, this study was limited to five urban contexts; only 150 photographs were purposively taken, analyzed and interpreted subjectively. It lacked interview tool of qualitative research for acquiring informative and symbolic meanings from the people which needs to imply for further study.

As the implication, this study adds knowledge about societal multilingualism by focusing on language choices, hierarchies, conflict and contact-phenomena, regulations, and aspects of literacy in the context of Nepal. It relates to a multitude of perspectives and disciplines like advertising, education, economics, history, media, semiotics, sociology, and urban geography. Furthermore, this research lies in establishing the linguistic landscaping as an insightful indicator, aspiration of enriching our knowledge of the social dynamics for the study of linguistic and social patterns of multicultural and multilingual societies in the major cities in Nepal including the capital, Kathmandu. Finally, the findings of the study can be useful for appropriate authority for linguistic policy in multilingual Nepal.

\section{References}

Awasthi, L. D. (2017). Language policy in federal Nepal' [Slide presentation] in M. Phil. second semester. Graduate School of Education. Kirtipur: Tribhuvan University.

Backhaus, P. (2006). Multilingualism in Tokyo: A Look into the Linguistic Landscape. In D. Gorter (Ed.), Linguistic landscape: A new approach to multilingualism (pp. 52-66). Clevedon, UK: Multilingual Matters.

Bastola, G. K. (2017). Critical analysis of the discourse used in hoarding board/advertisement. The Journal of Aadikavi, 7(1), 87-96.

Ben-Rafael, E., Shohamy, E., Amara, M. H., \& Trumper-Hecht, N. (2006). Linguistic landscape as symbolic construction of the public space: The case of Israel. In D. Gorter (Ed.), Linguistic landscape: A new approach to multilingualism (pp. 7-30). Clevedon, UK: Multilingual Matters.

Calvet, L. J. (1990). Des mots sur les murs. Une comparaison entre Paris et Dakar [The words on the walls. A comparison between Paris and Dakar]. In R. Chaudenson (Ed.), Des langues et des villes (Actes du colloque international a Dakar, du 15 au 17 de'cembre' 1990) (pp. 73-83). Paris, France: Didier'Erudition.

Cenoz, J., \& Gorter, D. (2009). Language economy and linguistic landscape. In E. Shohamy \& D. Gorter 
(Eds.), Linguistic landscape: Expanding the scenery (pp. 55-69). New York: Routledge.

Central Bureau of Statistics. (2002 \& 2011). National Population and Housing Census 2011

(National Report). Retrieved from: http://unstats.un.org/unsd/demographic/sources/census/wphc/

Nepal-Cesis-2011-Vol 1.pdf

Chanda, S. S., Hossain, M. A. \& Rahman, A. (2018). A case study of linguistic landscaping in

Bangladesh: Pabna context, Journal of ELT and Education, 1(1), 11-22.

Cohen, L., Manion, L, \& Morrison, K. (2007). Research methods in education. London and New York:

Routledge.

Constitution of Nepal. (2015). The secretariat of constituent assembly. Singhdurbar. Kathmandu.

Coulmas, F. (2009). Linguistic landscaping and the seed of the public sphere. In E. Shohamy \& D. Gorter (Eds.), Linguistic landscape: Expanding the Scenery (pp. 11-24). New York, NY: Routledge.

Dagenais, D., Moore, D., Sabatier, C., Lamarre, P., \& Aramand, F. (2009). Linguistic landscape and language awareness. In E. Shohamy \& D. Gorter (Eds.), Linguistic landscape: Expanding the scenery (pp. 253-269). New York, NY: Routledge.

Dixson, A. E. (2015). Analyzing the multilingual linguistic landscape of Buffalo, New York. A Master's Thesis. New York: University of New York.

Ethnologue (2019). Languages of the World. Nepal Ethnologue. Retrieved from: http://www.ethnologue. com

Foust, E., \& Fuggle, S. (Eds.). (2011). Word on the street: Reading, writing and inhabiting public space. London, UK: Institute of Germanic and Romance Studies.

Giri, R. A. (2015). The many faces of English in Nepal. Asian Englishes. 17(2), 94-115.

Gorter, D. (2013). Linguistic landscapes in a multilingual World. Annual Review of Applied Linguistics 33, 190-212. doi: 10.1017/S0267190513000020

Gorter, D. (Ed.). (2006). Linguistic landscape: A new approach to multilingualism. Clevedon, UK: Multilingual Matters.

Huebner, T. (2006). Bangkok's linguistic landscapes: Environmental print, codemixing, and language change. In D. Gorter (Ed.), Linguistic landscape: A new approach to multilingualism (pp. 31-51). Clevedon, UK: Multilingual Matters.

Hult, F. M. (2014). Drive-thru linguistic landscaping: Constructing a linguistically dominant place in a bilingual space. International Journal of Bilingualism, 18(5), 507-523. doi: 10. $1177 / 1367006913484206$

Kandel, B. (2018). The charm and attraction of English language to Nepali students. Discovery Dynamics, 4(2).

Landry, R., \& Bourhis, R. Y. (1997). Linguistic landscape and ethnolinguistic vitality: An empirical study. Journal of Language and Social Psychology, 16, 23-49.

Language Commission Nepal. (2015). Kathmandu: Nepal law books.

Malinowski, D. (2009). Authorship in the linguistic landscape: A multimodal-performative view. In E. Shohamy \& D. Gorter (Eds.), Linguistic landscape: Expanding the scenery. (pp. 107-125). New 
York, NY: Routledge.

Phyak, P. (2017). Multilingualism and diversity in language education. [Slide presentation]. M. Phil. second semester. Graduate School of Education, Kirtipur: Tribhuvan University.

Shohamy, E. (2006). Language policy: Hidden agendas and new approaches. New York, NY: Routledge.

Shohamy, E., \& Waksman, S. (2009). Linguistic landscape as an ecological arena: Modalities, meanings, negations, education. In E. Shohamy \& D. Gorter (Eds.), Linguistic landscape: Expanding the scenery (pp. 313-331). New York, NY: Routledge.

Shrestha, S. (2016). Role and status of English and other languages in Nepal. Journal of NELTA, 21(1-2). Shukla, P. \& Singh, S. K. (2018). Linguistic landscaping in India: With special reference to South Mumbai. Transframe. 3(4). North Eastern Hill University.

Spolsky, B., \& Cooper, R. L. (1991). The languages of Jerusalem. Oxford, UK: Clarendon.

Troyer, R. (2012). Linguistic landscape: Bibliography of English publications. Retrieved on: http:// www.wou.edu/ troyerr/linguistic_landscape_biblio.html

Wang, J. J. (2015). Linguistic landscapes on Campus in Japan: A case study of signs in Kyushu University. Intercultural Communication Studies, 24(1).

Basanta Kandel is a lecturer of English at Aadikavi Bhanubhakta Campus, Tanahun and a PhD scholar in English education, GSE, Tribhuvan University, Nepal. He is the Vice-chair of NELTA Tanahun. To his credit, he has published half-dozen of articles, edited journals, and presented papers in national and international conferences. His areas of interests include language policy, linguistics, research methodology, ELT, and phonetics and phonology. Besides, he is the Councilor of Federation of Nepalese Journalists and Editor of Vyasshree Newspaper. 